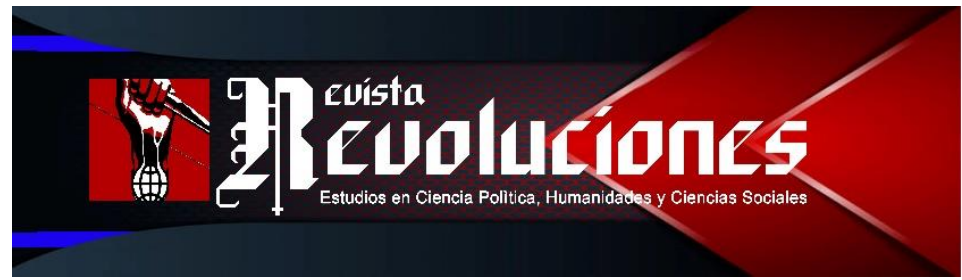

\title{
ENSAYO
}

\section{LOS NUEVOS MOVIMIENTOS DE LO POLÍTICO Y LA POLÍTICA EN TIEMPOS DE FIN DEL MUNDO}

\section{The new movements of the political and politics in times of the end of the world}

\author{
Nicol A. Barria-Asenjo ${ }^{1}$ \\ UNIVERSIDAD DE LOS LAGOS. DEPARTAMENTO DE CIENCIAS SOCIALES, OSORNO \\ CHILE \\ nicol.barriaasenjo99@gmail.com \\ https://orcid.org/o00o-0002-0612-013X
}

DOI: https://doi.org/10.35622/j.rr.2021.06.002

Recibido: 01-VII-2021 / Aceptado: 10-X-2021 / Actualizado: 01-XI-2021

\begin{abstract}
Resumen
El presente documento emerge como un intento de pregunta general frente a la coyuntura política contemporánea. Se propone pensar nuestro devenir histórico como un periodo de la historia de la humanidad inminentemente politizado. Sin embargo, con la llegada y uso con frecuencia creciente del concepto despolitización los matices actuales se vuelven confusos. El objetivo de este trabajo, fue pensar en los conceptos sobre los cuales giran los debates actuales. A partir de ese lugar, se generan aproximaciones a conceptos tales como política, político, izquierda, derecha y despolitización para finalmente ser enlazados superficialmente al escenario del Estado de Chile.
\end{abstract}

Palabras Clave: Política, despolitización, izquierda, antagonismo, siglo XXI.

\begin{abstract}
The present document emerges as an attempt to ask a general question in the face of the contemporary political situation. It proposes to think of our historical evolution as an imminently politicized period in the history of humanity. However, with the advent and often

\footnotetext{
${ }^{1}$ Escritora y ensayista por la Universidad de Los Lagos. Departamento de Ciencias Sociales. Osorno, Chile. Columnista y colaboradora en Le Monde Diplomatique Edición Chilena. Colaboradora en la Asociación Chilena de Revistas Científicas de Psicología. Asistente editorial en Revista Cuadernos de Neuropsicología Panamerican Journal of Neuropsychology. Ha participado y dirigido convocatorias nacionales en el campo de la psicología chilena. Cuenta con variadas publicaciones nacionales e internacionales, abordando temáticas de diferentes campos, entre ellos la investigación científica, el psicoanálisis, la filosofía y la política.
} 
ISSN: 2710-0499 ISSN-L: 2710-0480

increasing use of the concept of depoliticization, the current nuances become confusing. The aim of this paper was to think about the concepts on which current debates revolve. From that place, approaches to concepts such as politics, politician, left, right and depoliticization are generated to finally be superficially linked to the scenario of the State of Chile.

Keyword: Politics, depoliticization, Left, antagonism, XXI century.

\section{DESARROLLO}

Luego del obscuro periodo histórico de guerras mundiales que la humanidad tuvo que confrontar, obviamente, no de forma espontánea, emergieron nuevas formas de hacer política $\mathrm{y}$, diversas estrategias que buscaban sostener las formas de política existentes. El amplio alcance que ya tenía la política y lo político², comenzó a enlazarse a otras esferas humanas y/o sociales, por lo cual, los márgenes conceptuales que hasta ese momento deambulaban entre los umbrales y movimientos de la historia sufrieron una nueva ruptura, una fisura sistemática se comenzó a inevitablemente sentir en el terreno teórico, acompañado de constantes modificaciones y reformulaciones que persisten hasta los días de hoy ${ }^{3}$.

No solo las guerras mundiales marcaron un antes y un después en las configuraciones sociopolíticas y el porvenir. Una sintonía similar, en relación a la potencia transformadora tuvo, por ejemplo, el mayo francés. La década del 60 en general, trajo consigo una revolución teórica, social, conceptual, cultural y humana. Recordemos que, en esta fecha las luchas políticas y procesos de insurrección popular comenzaron a sentirse en las calles, liderados en buena medida por intelectuales que buscaban incorporar sus líneas de pensamiento en la práctica. Nuevos escenarios políticos y nuevas estrategias hicieron presión en la telaraña ideológica de ese entonces.

Además, es necesario mencionar, la irrupción de los movimientos feministas, la efervescencia de los movimientos ecologistas. En suma, los engranajes sociales y políticos comenzaron a moverse en una dirección no evaluada por la clase dominante y el orden social en su expansión, produjo que emergiera un nuevo orden social y en paralelo el proceso de desfiguración de lo establecido, es decir, el clásico paso de lo viejo a lo nuevo, impuso una

\footnotetext{
${ }^{2}$ Según Retamozo (2009) La distinción de lo político y la política, así como la idea de la primacía de lo político sobre lo social, han adquirido un estatus privilegiado en el estudio de algunos de los problemas políticos contemporáneos. Dos de los temas que han sido referentes de estas discusiones giran en torno a las preguntas por la conformación, y disputa, del orden social, por un lado, y la constitución de los sujetos políticos (p. 70).

${ }^{3}$ Conviene agregar la perspectiva actual planteada por Gómez (2017) para quien "El campo académico de las ciencias sociales y el pensamiento social contemporáneo desde hace ya por lo menos cuatro décadas ha consolidado dos tendencias teóricas: la pérdida de centralidad y la secundarización de la importancia de las clases sociales y la separación neta de los fenómenos de movilización social del análisis de clases. La reducción del potencial explicativo de la teoría de las clases sostenido por algunos que hablan de la "muerte de la clase" se suele convertir en una suerte de veto conceptual cuando se aborda la problemática de los movimientos sociales y la acción colectiva. Si la perspectiva del análisis de clase se encuentra en franco retroceso en general, con respecto a los movimientos sociales se encuentra en una situación de divorcio teórico. Las duras inercias de los paradigmas establecidos tienden a naturalizarlos como conceptos alternativos o directamente enfrentados" (párr. 1).
} 
nueva demanda consistente en un nivel superficial en la necesidad de una nueva revolución conceptual. La práctica forzando a la teoría.

A propósito de lo anterior, encontramos una suerte de recorrido histórico-conceptual, realizado por Marcelo Gómez (2017), cito en extenso:

Hasta dentro mismo del diversamente inabarcable pensamiento marxista se sienten tendencias a la atenuación de la dimensión clasista del análisis de los procesos sociales y políticos de lucha y movilización. Para algunos (Offe, 1988) los movimientos están lejos de reemplazar a las clases, pero tienen su importancia para explicar una nueva fisonomía del conflicto social y político en las democracias del capitalismo avanzado. Para otros (Kärner, 1983) más cercanos a las tradiciones del marxismo, hay que cavar una fosa teórica y tratar los nuevos fenómenos contestatarios (ecologistas, feministas, contracultura, etc.) cómo universos paralelos al de las clases sociales. Desde las fábricas y los lugares de trabajo la lucha de clases canónica sigue sobredeterminando al resto, a riesgo de reducir la clase a un concepto atrapado en la sociología del trabajo y de la empresa. Frente a la vasta tradición marxista de criterio estructuralista, comenzaron a desarrollarse un gran número de investigaciones y nuevos conceptos que fueron dando forma al campo disciplinar específico de la sociología de los movimientos sociales y la acción colectiva. El señero trabajo de Smelser de 1965 introduce la cuestión en la sociología americana típicamente funcionalista proponiendo una formalización teórica general para abordar el comportamiento colectivo. Después Touraine hará lo propio para la sociología europea en el marco de las teorías de la sociedad posindustrial poniendo en juego conceptos como actor, identidad y acción histórica. La explícita escotomización o relegamiento de la cuestión de clase opera desde el nacimiento mismo de estas teorías. La tradición neoutilitarista e instrumentalista americana y la tradición culturalista y expresivista europea alimentan a partir de los años '8o el campo de estudios de la acción colectiva. Ambas tradiciones hacían profesión de fé de categorías analíticas que se planteaban como competitivas o alternativas a las de clase. La irrupción de los trabajos de Charles Tilly y Sidney Tarrow contribuyeron a especializar y focalizar aún más el campo temático a través de conceptos como movilización de recursos, estructuras de movilización y oportunidades políticas. En los años '90 los americanos (Snow, Benford y otros) desarrollan la teoría de los enmarcados interpretativos buscando abordar los componentes simbólicos y culturales que quedaban fuera de la matriz instrumentalista (...) Las irrupciones de masas y los movimientos sociales en sus complejas y diversas formas y orientaciones mantienen el tenor principal de la dinámica de la escena política donde las clases sociales ya no juegan un papel relevante ahora localizado en el discurso y el antagonismo político.

Es precisamente el último punto lo que parece quedar en duda en relación a los procesos políticos que han tenido lugar en lo que va del tercer tercio de nuestro siglo, de este agitado y confuso siglo XXI. Conviene preguntarnos: ¿Los procesos de insurrección popular funcionan independiente de la cuestión de clases? ¿Sin incorporar o pensar en la cuestión de clases, la desigualdad y la inequidad social es posible entender el escenario global que gatilló los movimientos sociales de nuestra época? ¿Cómo pensar en dinámicas políticas o revueltas populares sin enlazarlo a los escenarios económicos en que los manifestantes viven? 
ISSN: 2710-0499 ISSN-L: 2710-0480

En esta breve reflexión, a lo que se apela es a construir diferentes preguntas, generar diverso espacio de reflexión, y evitar caer en respuestas vacías, apresuradas o aquellas que terminan sumándose al mismo punto muerto que una y otra vez las producciones teóricas, clásicas o contemporáneas parecen alcanzar. A partir de este punto, nuestra metodología ${ }^{4}$ será generalmente Foucaultiana (1970-1971) pues, ese prisma interpretativo ayuda a plasmar o indagar en nuevos rincones teórico-conceptuales, recordemos que, Foucault en su texto "Lecciones sobre la voluntad del saber: Curso en el College de France" afirmó que: "todos los hombres, por naturaleza, desean saber... ¿Qué hombre, por tanto, no es filósofo, y cómo no habría de ser la filosofía lo más necesario del mundo?” (p.20).

Es innegable que el texto previamente citado, fue construido en otras condiciones materiales, ideológicas, históricas y espirituales, tiempos antagónicos tal vez con otro devenir social, pese a esa divergencia de base, el texto y las palabras retornan volviendo adecuadas para nuestra época por la coyuntura política que nos acompaña.

Tiempos ajetreados, rebeldes, volátiles $\mathrm{y}$, en el cual la rapidez parece ser una variable importante frente a la aparente imposibilidad de detenerse y pensar sobre las condiciones actuales, las decisiones tomadas que nos arrastraron como humanidad a este confuso presente y las decisiones y cambios que tienen que tomarse para alterar el cada vez más evidente fin del mundo.

Ahora bien, uno de los objetivos específicos de este trabajo es intentar generar una aproximación a los Antagonismos del siglo XXI, poniendo énfasis en el escenario latinoamericano, un objetivo ambicioso, y una tarea en buena medida imposible de alcanzar. Es por eso que, la humildad de la palabra se vuelve crucial, he decidido incorporar "una aproximación”, pues, no solo este análisis, sino, cualquiera que se intente realizar, no será mejor ni peor que los muchos intentos que ya hay en la academia, intentos fallidos y vacíos por delimitar el contexto regional, local o global.

El hecho de que no se logren objetivos en su totalidad, no significa que haya una decadencia creciente en la izquierda teórica, es solo que la potencia de los giros de la historia hace escurridizo cualquier fenómeno. Lo importante es la constancia frente a los intentos desesperados por lograr capturar la escurridiza y en constante movimiento situación continental y global.

\footnotetext{
${ }^{4}$ Respecto de la metodología, es menester esclarecer que hay una dirección filosófica que subyace y acompaña el proceso, recordemos que para Foucault (2012) la filosofía, que desempeña en verdad el papel de conocimiento supremo -conocimiento de los primeros principios y conocimiento de las causas últimas-, tiene también el papel de envolver desde el inicio todo deseo de conocer. Su función consiste en garantizar que lo que surge como verdadero conocimiento en la sensación, en el cuerpo, sea ya, por naturaleza y en virtud de la causa final que lo dirige, del orden de la contemplación y la teoría. Su función es también garantizar que el deseo no sea, a pesar de las apariencias, ni anterior ni exterior al conocimiento, porque un conocimiento sin deseo, un conocimiento dichoso y de pura contemplación, ya es en sí mismo la causa de ese deseo de conocer que tiembla en el simple agrado de la sensación (p. 29).
} 
Retomando, las distinciones entre la política y lo político, son fundamentales para poder repensar los antagonismos de nuestra época, ahora bien, en pleno 2021, hemos de incorporar otra variable, y es el concepto o noción de "Despolitización”, concepto cada vez más utilizado, pero que, principalmente es utilizado por la derecha política. La despolitización de lo imposible de despolitizar es al parecer uno de los objetivos que la derecha radical incorpora en sus programas o de forma más específica en sus propuestas y proyectos políticos. Augurios de una política despolitiza como producto comerciable e intercambiable por la dignidad que las masas populares reclaman.

En Chile, la situación es fácil de identificar, se prevalente transgeneracionalmente en una suerte de cambio radical en el duopolio político existente desde incluso antes del periodo cívico-militar, desde la revuelta de los pingüinos, hasta la revuelta del 18 de octubre del 2019, el orden social y lo simbolismos han estado en constante movimiento, siendo sistemáticamente reemplazado y fisurados. El terreno de lo simbólico, de lo social, de lo material y el mundo afectivo ha estado en disputa constante, un caso específico que contiene elementos que permiten la generalización. Situación similar hemos visto en los movimientos sociales de Colombia, Perú, México, donde, además, no han quedado de lado la vulneración de los derechos humanos en todos los niveles existentes. Elementos, escenario y condiciones que se repiten una y otra vez.

Continuando con el caso chileno, en vísperas del proceso de cambio de presidente, hay un persistente intento por despolitizar la política misma, este es uno de los mensajes no metafóricos sino directos que ha enviado el candidato a la presidencia que es seguidor y discípulo de Sebastián Piñera. El legado neoliberal intenta nuevamente transformarse en algo más allá de lo mismo, una repetición mutante de lo mismo, pero con diferente nombre.

¿Es posible despolitizar la política? Por supuesto que no. Sin embargo, mediante esa estrategia política-discursiva, se captura lo escurridizo. Lo importante en este punto muerto de la política chilena, es que la derecha acusa a la izquierda de intentar politizar la política. Y en países en desarrollo, con eslóganes falsos de paraísos, en los cuales un gran porcentaje de la población ha sido limitada en educación, calidad de vida y equidad social, la palabra "política", "justicia", "libertad" y otras tantas son términos explosivos. Uno de los mensajes que logra vender la derecha es que hay que ir en contra de la política porque es la política lo que tiene mal al país, en buena medida esto es verdad, pero se olvida de asumir cualquier responsabilidad ces la política o es la clase política la que tiene al mundo en crisis permanente? ¿Es la política, lo político o Los Políticos los que operan cómo ente destructor de formas dignas de existir?

Otra acusación persistente en nuestro tiempo, es el intento por demostrar que la izquierda política, va en contra de la tradición, y, en este sentido, es la derecha el superhéroe de la tradición, la cultura y los valores. Punto que ha sido abordada por el sociólogo estadounidense Vivek Chibber (2021) para quién la cuestión se resume a lo siguiente: 
ISSN: 2710-0499 ISSN-L: 2710-0480

Pero entonces, ¿qué diferencia esta defensa de la tradición de la que emprende la derecha? Lo cierto es que ninguno de los dos bandos adopta la posición de una defensa o de una condena de la tradición en general. Cada uno selecciona ciertos elementos de la cultura que encajan con sus objetivos políticos y es más bien hostil o indiferente frente a aquellos que no lo hacen. Cada lado busca fortalecer esas partes de la cultura que se alinean con sus objetivos y debilitan a su oposición. Para la izquierda esto significa realzar las tradiciones que fortalecen al trabajo frente al capital. Pero subyace a todo esto un principio más profundo: los elementos de la cultura que deberían preservarse son aquellos que socavan cualquier tipo de poder ilegítimo. En la actualidad, el poder del capital sobre los trabajadores es el ejemplo más importante en este sentido. Pero el mismo principio aplica a otras formas de dominación: género, raza, identidad étnica y nación.

El producto contingente de la hegemonía, es decir, la sociedad, se remueve según la potencia de los discursos con mascara "contra-hegemonica". Sin embargo, muchos proyectos emancipatorios, muchos proyectos contra-hegemonicos, contienen encriptado en sí mismo aquello que pretenden falsamente erradicar. Estamos en tiempos profundamente marcados por el devenir irracional, por la co-construcción presente de mitologías políticas del futuro y, procesos socio-políticos que solo apelan a utopias y mover engranajes históricos que aseguran la repetición. Lo que subyace a estos falsos movimientos de la historia y de lo social que tienen lugar una y otra vez, es evidentemente un mero reemplazo de una ideología por otra más y más voraz

Cuestión que Marx y Engels ya plantearon, desde tempranas datas. La coyuntura política una y otra vez nos hace retornar a las herramientas teóricas del pasado, repetición constante y casi imperceptible de la historia de la humanidad.

En esto, el orden social, toma un lugar central, pues, es ese el punto o núcleo al cual la ideología apunta, allí se encuentran los engranajes fundamentales de lo establecido, es la telaraña que permite finalmente la existencia o co-existencia del modelo capitalista neoliberal, respecto del "orden social”, no es un debate novedoso, por ejemplo, Retamozo (2009) menciona al respecto:

En efecto, la preocupación que orientó a las utopías renacentistas de Campanella y Moro fue la de pensar órdenes sociales alternativos a partir de la proyección imaginaria de comunidades. Un enfoque al mismo asunto, pero no desde la utopía sino desde la política real, es la que propone Maquiavelo. Si algo vincula a El príncipe y los Discorsi es la motivación de analizar las diferentes opciones ordenantes de la sociedad y los recursos para reproducirlas. La pregunta clásica por el orden social adquirió en la modernidad mayor relevancia a partir de la secularización del mundo. La contraposición de Hobbes y Spinoza, recuperada por autores contemporáneos supone reconstruir el debate por la legitimidad del orden social moderno, el cual, frente a la cada vez mayor imposibilidad de remitirse a un plano divino, requirió otras formas de legitimación en lo secular. Así, la teoría política de Hobbes avanza sobre la misma pregunta ¿̇no es acaso el Leviatán la personificación del nuevo orden social que estructura el caos y busca acabar con el estado de guerra perpetua? A su tiempo, algo similar inspiró la teoría del gobierno civil en Locke y el contractualismo roussoniano y kantiano. El problema del orden social (y su reverso, el conflicto), asociado con la razón, la 
libertad y la legitimidad, constituye uno de los ejes fundamentales del pensamiento político moderno. En el siglo XXI tanto Hegel como Marx se enfrentaron al problema de lidiar con el asunto del orden y el conflicto planteado en estrecha vinculación con el asunto de la unidad, la universalidad y la historia. Por vías análogas y a la vez disímiles, intentaron clausurar el conflicto en una recuperación del universal. Ambas filosofías de la historia así lo permiten a partir de una concepción trascendental: el despliegue de la idea o la realización de la clase como universal. El paso de un orden social contradictorio y conflictivo a una recuperación superadora del orden armónico para los destinos de la humanidad subyace a gran parte de los esfuerzos hegelianos y marxistas como promesa de plenitud (p.71).

Podríamos continuar el trabajo del autor mencionando diferentes análisis sobre la cuestión, tomar las aporías de la Grecia antigua, los aportes de Ranciere, del filósofo Slavoj Zizek y un sin fin de intelectuales que han abordado sin miedos la cuestión, la lista es extensa. Sin embargo, es necesario reconocer que el complejo devenir de nuestros tiempos, el conflicto permanente, nos lleva a incorporar la misma tesis del inicio de esta reflexión, solo podemos aportar pequeñas miradas, acercamientos o aproximaciones, la velocidad de nuestra época, imposibilita cualquier captura.

\section{A modo de cierre, dejaré las palabras de Terry Eagleton (1997) quién señala:}

Sin embargo, si las ideologías dominantes suponen a menudo falsedad, ello se debe en parte a que, de hecho, la mayoría de las personas no son cínicas. Imaginemos una sociedad en la que todo el mundo fuese o cínico o masoquista, o ambas cosas. En esta situación, no habría necesidad de ideología, en el sentido de un conjunto de discursos que oculten o legitimen la injusticia, porque a los masoquistas no les importaría su sufrimiento y los cínicos no tendrían problema en vivir en un orden social explotador. De hecho, la gran mayoría de las personas tienen una conciencia muy sensible de sus propios derechos e intereses, y la mayoría se sienten incómodas ante la idea de pertenecer a una forma de vida muy injusta. Así pues, o bien deben creer que estas injusticias están en vías de ser corregidas, o que están compensadas por beneficios mayores, o que son inevitables, o que en realidad no son injusticias. Inculcar estas creencias es parte de la función de una ideología dominante. Puede hacerlo o falseando la realidad social, suprimiendo y excluyendo ciertos rasgos impresentables de ésta, o sugiriendo que estos rasgos no pueden ser evitados. Esta última estrategia tiene interés desde la perspectiva del problema verdad/falsedad. Pues en relación con el sistema actual puede ser verdad que, por ejemplo, es inevitable cierto nivel de desempleo, pero no en relación con una alternativa futura. Los enunciados ideológicos pueden ser verdaderos en relación con la sociedad en su estado actual, pero falsos en cuanto sirven para descartar la posibilidad de una situación transformada. La verdad misma de estos enunciados es también la falsedad de su negación implícita de que pueda concebirse algo mejor. Así pues, si en ocasiones la ideología es falsificadora lo es por razones en conjunto más bien esperanzadoras: el hecho de que la mayoría de las personas reaccionan vivamente al trato injusto, y de que a la mayoría de las personas les gustaría creer que viven en condiciones sociales razonablemente justas. Por ello, resulta extraño que algunos radicales afirmen que el engaño y la ocultación no desempeñan ninguna función en el discurso ideológico dominante, pues tener una perspectiva política radical le compromete a uno a la concepción de que el orden social vigente está marcado por graves injusticias. Y ninguna clase dominante interesada en conservar su credibilidad puede permitirse reconocer que estas 
injusticias podrían rectificarse mediante una transformación política que las erradicase. Así pues, si la ideología en ocasiones supone distorsión y mistificación, es menos por algo inherente al lenguaje ideológico que por algo inherente a la estructura social a la que pertenece el lenguaje. Hay ciertos tipos de intereses que sólo aseguran su dominio mediante la duplicidad; pero esto no significa que todos los enunciados utilizados para promover esos intereses tengan que ser engañosos (p. 50-51)

Nuestro devenir histórico, lo que genera, es una mutación del discurso que previamente el cambio de siglo ha contaminado o colonizado, proceso sistemáticamente agenciado por las lógicas dominantes de cada periodo histórico. Entonces, es menester considerar que, la repetición histórica no es una repetición de acontecimientos, consiste más bien, en una reacomodación o transfiguración del discurso anterior, la forma en que este devenir tiene lugar, es mediante una implantación de un nuevo discurso que se co-construye en las entrañas del anterior. Siguiendo esta idea, lo que se puede asegura a propósito de la época siguiente a la nuestra es que habrá una nueva mutación del discurso nuclear que ha acompañado a la historia de la humanidad desde el inicio de los tiempos. La falsa ideología pura persistirá como mito político o utopía.

\section{REFERENCIAS BIBLIOGRÁFICAS}

Castoriadis, C. (1986). El campo de lo social histórico”, en Estudios: Filosofía-Historia-Letras, núm.4. http://estudios.itam.mx/sites/default/files/estudiositammx/files/oo4/ooo169665.pdf

Chibber, V. (2021, February 8). Larga marcha del laborismo. Jacobin. https://www.jacobinmag.com/2021/o8/labors-long-march

Eagleton, T. (1997). Ideología. Una introducción. Barcelona: Paidós.

Foucault, M. (2012). Lecciones sobre la voluntad de saber: curso en el Collège de France (1970-1971) seguido de "El saber de Edipo. - 1a ed. - Buenos Aires: Fondo de Cultura Económica.

Gómez, M. (2017). Análisis de clase, movimientos sociales y antagonismo: saliendo de la parálisis teórica. Theomai, núm. 36, pp. 94-118.

González, R. (2015). ¿Antagónicos ideológicos o pragmáticos políticos? El navismo y sus dinámicas aliancistas. Revista de El Colegio de San Luis, 5(9), 100-136. Recuperado en 28 de septiembre de 2021, de http://www.scielo.org.mx/scielo.php?script=sci_arttext\&pid=S1665899X2015000100100\&lng=es\&tlng=es. 